\title{
Performance auditing-addressing real or perceived expectation gaps in the public sector
}

\section{Pat Barrett AO}

The growth of performance auditing in Australia (and in many other countries) has led to a range of seemingly conflicting observations about their contribution to better public administration, which basically reflect differing political and public expectations of such audits. Confusion also revolves around the question of just what value is being assessed, reflecting differing perceptions of assurance and performance and of the coverage of administrative and policy effectiveness. A better understanding of what needs to be achieved by those responsible and acceptance of accountability for the required results would improve confidence in public administration and in the value that it delivers. We should always keep in mind the requirement for quality, as well as relevant, audit reports if any kind of expectation gap is to be minimized, preferably removed.

At the outset, I want to stress that I am talking about 'auditing', which involves a number of professional requirements and constraints. As with the debate about accounting and auditing in the private sector, particularly during the last two world financial crises, these disciplines bear directly on real or perceived gaps in the expectations of what constitutes an 'audit'. Unfortunately, any confusion in this respect seems to be more exaggerated in the case of performance, as opposed to financial statements, audits. For many, the latter is a 'black hole' requiring explanation, whereas the former covers government programmes about which everyone has a view and, often, a personal interest. Such interest is frequently reflected in discussions about 'who pays' and 'who benefits' . Less self-focussed is the broader question about the 'public interest' which is often quoted but seldom defined. The Australian National Audit Office (ANAO, 2008a, p. 3) defines a performance audit as: 'an independent, objective and systematic assessment of public sector entities' programs, resources, information systems, performance measures, monitoring systems and legal and policy compliance'.

While I draw largely on the ANAO's experience, reference is also made to practices in other countries, in particular, the UK, USA and New Zealand. The focus is primarily on three areas where audit expectation gaps can occur-the application of professional standards, accountability for audit performance and in the implementation of audit recommendations. The context is an environment with over 30 years of experience with performance auditing and a robust legislative framework that creates expectations in the parliament and in the general public (ANAO, 2011a).

\section{The standards framework}

Addressing the probably least interesting, but highly relevant, aspect of this topic first, I note that professional standards are integral to the conduct of audits. While the Auditor-General Act 1997 requires the Australian AuditorGeneral to establish and publicise auditing standards, in essence they largely reflect the standards developed by the Australian Auditing and Assurance Standards Board. In turn, the latter also reflect the International Auditing Standards.

The Australian Auditor-General, Ian McPhee, has said that the issue of the auditing standard (ASAE 3500) in 2008 'was a significant milestone in the evolution of performance auditing' (McPhee, 2010). This in part reflected the paucity of performance audit standards and replaced two earlier standards (AUS 806 and AUS 808)' which were mainly statements of principle and intent. The latter can be both a strength and a weakness. A particular statement in the standards always struck a chord with me: "The work undertaken by the auditor is
Pat Barrett AO is a senior fellow, Australian National Centre for Audit and Assurance Research, College of Business and Economics, Australian National University, Canberra. He was formerly AuditorGeneral for Australia. 
permeated by judgement'. Examples were: 'deciding the nature, timing and extent of audit procedures' and 'the drawing of conclusions based on the audit evidence gathered'. In this respect, I would simply observe that judgement is contestable but evidence should, ideally, not be. It should be a reasonable expectation that there would be agreement on the 'facts'. More about that later.

McPhee went on to argue that ASAE 3500 introduced greater discipline to performance auditing (McPhee, 2010). While such discipline is important for accountability and confidence in performance auditing, it also facilitates understanding of what should be expected of performance audits.

The standard requires compliance with the fundamental ethical principles of integrity, objectivity, professional competence and due care, confidentiality and professional behaviour (Auditing and Assurance Standards Board, 2008). These requirements are reinforced by both the Auditor-General Act 1997 and the Public Service Act 1999 in Australia. They are necessary conditions for public confidence in public sector performance auditing, but do not guarantee relevance in timing and coverage nor the audit outcome in terms of quality and usefulness of recommendations and associated reporting. Professional standards and legal requirements are disciplines on the audit processes but judgements have to be made about the results being achieved by those processes. That largely comes down to realistic and robust performance assessments (and related measures) and, importantly, accountability for performance.

\section{Accountability for performance}

Openness and transparency are the major strengths of the audit process, reinforced by audit independence. Much has been written about audit independence (for example Barrett, 2010a; ANAO, 2011a) and I do not cover the extensive debate here. However, it has been generally agreed that audit legislation has been a major factor in the provision and maintenance of audit independence. Reference has been made to 'model' legislation, for example in the UK, Canada, Australia and New Zealand. Basically, independence was simply indicated as the auditor-general not being able to be directed as to what, how or when to audit. In the context of expectation gaps, it is particularly important for an auditor-general to be able to demonstrate accountability for the exercise of independence as a means of promoting understanding of, and confidence in, audit outcomes.

\section{Audit selection and programming}

Any audit expectation gap is frequently reflected in criticisms about the 'what' and 'when' to audit decisions. On the one hand, an auditorgeneral can be criticised for being too acquiescent to pressures applied by particular groups such as the government, the opposition, the public service, the media, and individual or collective community organizations. Disappointment is sometimes expressed about the 'opaque' nature of audit conclusions and recommendations. This may be due to audit selection, or the fact that the audit is simply 'a good news story'. Surprisingly, an audit that largely reports good performance is frequently not regarded with a great deal of interest. Unfortunately, there is also at least the 'unstated' but sometimes 'implied' view that the audit was 'ineffective'. Such criticism, if warranted, would most probably be the result of the selection processes and/or poor audit performance. The remedy for these deficiencies is largely in the hands of the audit office. Fortunately, such deficiencies can be shown to be the exception rather than the rule.

Audit selection and an audit programme are significantly determined by the availability of resources both in quantity and professional expertise. Given the limited audit resource base and the extent of the mandate coverage, selection has to be risk-based and involve judgement. In Australia, the Joint Committee of Public Accounts and Audit (JCPAA) plays an important role in both processes, as well as in the determination of the Audit Budget. The JCPAA has the responsibility for reviewing the annual resource requirements and operations of the ANAO and determining the audit priorities of the parliament. Without explanation, such provisions may appear to be contrary to requirements for audit independence. However, in practice, the reverse is the case, for example with the JCPAA being able to review the ANAO's budget estimates in relation to its workload, particularly reflected in its audit programme, and the JCPAA's determination of parliament's audit priorities.

In the Australian situation, questions have been raised as to whether the frequency of government requests for audits and the consequent pressure on the auditor-general affects the latter's independence. In particular, the process (assurance) oriented nature of such requests was seen as a possible deliberate strategy to lower the ANAO's capacity to 
undertake value-for-money programme performance audits. At the very least, the number and complexity (particularly in terms of resource demands) of government-requested audits would have a marked impact on the completion of any audit programme. Any public misconception about the processes bearing on the selection of performance audits and any subsequent 'gap' in expectation of the outcomes to be achieved could be largely ameliorated by the government referring any audit requests to the JCPAA for review. This would reinforce the non-political role of the JCPAA, as well as its authority and effectiveness. Nevertheless, the ultimate decision has to be made by the auditorgeneral.

A major issue for performance auditing is the maintenance of parliamentary and public confidence in the coverage, timeliness and outcomes of such audits, as well as effective action to ensure proper implementation of any recommendations and conclusions. In my view, the confidence, co-operation, involvement, and commitment of the organizations and people being audited is also a factor that needs to be kept in mind. In a number of respects, this is where there are apparent and real expectation gaps leading to limited or no improvements with flow-on consequences for other stakeholders and their level of confidence in performance auditing. Audit offices generally recognize this 'reality' and endeavour to involve those stakeholders in the strategic planning and audit programming processes. This is well illustrated in the comprehensive work programme undertaken each year by the ANAO (ANAO, 2010a).

One advantage is to minimize unnecessary duplication of activity on other reviews and evaluations and the often considerable costs involved. Where it is decided to go ahead with a performance audit and another review, the timing of each activity can not only achieve highly efficient and effective complementation of coverage, analysis and reporting but also a comprehensive and integrated approach to improving the relevant programme outcomes. In other words, one activity can 'reinforce' and give greater credibility to the other.

Some question too close an involvement with auditees as a potential erosion of audit independence. Ironically, they do not see the same problem with any consultation or insights provided by 'clients' of auditees, the general public or even media. A distinction should be made between obtaining information (expertise) and the exercise of judgement and decision-making. A quite common criticism of auditors, particularly in the conduct of performance audits, is that they do not really understand the changing environment in which the auditee has to operate, the various pressures being applied, the management and technical complexities involved and the factors impacting on the auditee's achievement of required results. Close involvement and co-operation with auditees, particularly in the strategic planning and programming stages of performance auditing, can provide significant 'dividends' for all parties in their own understanding of issues that impact on performance ranging from the governance framework through to actual service delivery and the associated accountability requirements. For auditors, this approach has been an important part of building credible and useful knowledge management systems, which enhance audit capability, lessen auditee frustration in having to continually 'educate' auditors about their agency's operations, and improve audit efficiency, including lower audit costs for both the audit office and the auditees.

\section{Performance assessment}

The focus of this article is largely on two aspects of audit performance and its assessment - the conduct of performance audits and related reports and the implementation of findings and recommendations. Both aspects are impacted by audit selection and programming and any consequential 'expectation gaps' that need to be addressed, such as just what is the 'value' being assessed as part of the focus of much of performance auditing on 'value for money' achieved. I discussed this issue in an article included in this journal in 2010 (Barrett, $2010 \mathrm{~b})$. The research involved pointed to both 'real' and 'perceived' expectation gaps, which can apply more broadly to the outcomes of performance audits.

From an examination of performance assessment and reporting across a number of audit offices (Australia, New Zealand, Canada, USA, and the UK), there is a sound basis for public (and political) confidence in the accountability measures in place. In particular, there is a high level of transparency and explanation of performance assessments, including extensive involvement of major stakeholders by those offices (see ANAO, 2010b, pp. 24-48; NZ Controller and Auditor-General, 2010, pp. 14-18; GAO, 2010). Reports are subject to quality assurance reviews, including adherence to relevant auditing standards and to professional practice requirements. A major thrust of audit office performance has been to 
'add value' to public administration. Perceptions about just what this means are therefore central to any assessment about that performance.

Looking across the audit offices mentioned above, the UK National Audit Office (NAO) places significant emphasis on measurement of financial impact on benefits achieved. On the front page of the NAO's annual report for 2011, the following statement highlighted its performance as follows: 'Our work in the year led to audited financial impacts of more than $£ 1$ billion, improved services to citizens, and increased transparency and accountability' (NAO, 2011). The UK Comptroller and Auditor General, in a response to my earlier PMM article, observed that: "performance audit carries far more weight where we can quantify the gap between current performance and the outcomes envisaged by policy-makers' (Morse, 2010).

Similarly, the US Government Accountability Office (GAO) puts considerable weight on its achievement of financial benefits in its annual documentation (GAO, 2011a, 2011 b, p. 6). For 2010, financial benefits were assessed at \$US 49.9 billion. These are significant amounts and lead to the question as to just what benefits can be actually achieved and by when. There have also been questions about the audit associations of 'cause' and 'effect' in determining the attribution of such benefits. One test might be any action by treasury departments to 'harvest' such savings.

Auditees often claim such benefits come from their own learning and insights, as well as from those the auditors may have gleaned from their wide experience. However, the general public would probably only be interested in the actual achievement of the financial benefit. Consequently, there are perception issues that need to be addressed. More importantly, there may well be duplication in attributed performance improvements between the relevant stakeholders. There is no guarantee that, even in the USA where the GAO has a quite disciplined approach to verifying and validating performance data (GAO, 2011c), there is no such duplication.

In other countries, such as Australia, much lower estimates of financial impacts/benefits are generally identified. The estimated 'savings' in individual reports generally depend on the relevant agencies/departments taking identified action such as 'being more proactive', 'rationalizing reporting mechanisms', and 'better matching of program payments to local government' (ANAO, 2006). Such comments reflect the often management/administrative efficiency and cost-effectiveness orientation of performance auditing. This should not be surprising in countries such as Australia, New Zealand and the United Kingdom, where the auditors-general are precluded from commenting on government policy. Nevertheless, as Morse (2010, p. 324) observed: 'If our purpose is to effect change, we need to go beyond providing assurance and making judgements by advising audited bodies on how they might improve their performance'; recommendations 'must flow from solid evidence of what works' without being overly prescriptive. This, unfortunately, is fertile ground for misconceptions to arise as to who is responsible for performance improvements or lack of them.

Real or apparent expectation gaps, in relation to such outcomes, and cause/effect debates, frequently result from a lack of understanding and/or unrealistic expectations of performance auditing and of the public sector. While my research indicates that audit offices have increasingly provided better public explanations and documentation of the various audit processes and results, the same cannot be said about public sector programmes and results achieved. Performance measures continue to be largely related to processes and outputs, not programme outcomes. In part, this is because other levels of government and the private, including not-for-profit, sectors actually deliver those outcomes. An added complication has been the development of more "joint arrangements' with a lack of clarity about the responsibilities/accountabilities involved. The use of 'lead agency' arrangements and 'partnership agreements' have not made a demonstrable difference in these respects.

Many factors impact on the development of credible, reliable and meaningful performance measures and their assessment, particularly in quantitative terms. Qualitative measures are often easier to articulate and can provide greater confidence if properly constructed. Many government programmes have long-term objectives with the results not being apparent for 10, 20 or more years. Audit offices have recognized these difficulties and have produced better or best practice guides (ANAO, 2004; NAO, 2009) and encouraged the use of 'intermediate outcomes' to simplify and facilitate useful performance information. It is important to recognize that it is the agency/ department's corporate governance, management, operations and results that are being audited. The audit can determine whether there is appropriate and useful 
performance information or not. If there is, the performance audit can opine on the measure's suitability for the purpose and the extent to which the performance required is achieved. It is not the auditor's responsibility to determine more suitable measures and audit performance against them. Unfortunately, this is often an expectation of the media and of some politicians.

This raises one issue for consideration in meeting an apparent expectation gap in relation to programme performance and audit. Many of us have had experience with government programmes which have outlived their usefulness. As well, we know of programmes which are either not capable of meeting the specified objectives (or intentions) or are only partially doing so. Policy failures may be due to inefficient and/or ineffective governance and administrative arrangements for implementation such as in the case of the recent home insulation program (ANAO, 2010c) in Australia. However, such failures may also be due to other factors such as 'changed circumstances', 'deficient policy advice' or 'lack of engagement/response by the target group'. The expectation would be that the relevant agencies/departments would bring any such 'failures' to the attention of relevant ministers with suitable advice as to alternative courses of action. However, experience shows that there is often reluctance to indicate that 'the emperor has no clothes'. While it is clearly inappropriate for an auditor-general to comment on government policy (prohibited in many jurisdictions), it would seem helpful to the parliament, and to the government, to be made aware as to whether action being taken is likely to achieve the policy objectives specified, efficiently and effectively. This is quite different to questioning the objectives themselves, including as to whether any 'failure' is due to policy weaknesses.

\section{Implementation of audit recommendations}

Perceptions about performance are often largely influenced by the results achieved. How the results are being achieved is also important. While audit selection and programming outcomes are reflected in audit findings, conclusions and recommendations, and should influence perceptions, separate judgements will still be made about the effectiveness of those outcomes. Performance measures are essential for judgements about the professionalism, cost, quality, and conduct of audits. Such measures are regularly reported by audit offices and subject to independent, as well as peer, review examination and public reporting. A number of reviews are conducted each year by the internal auditors, independent private sector experts, and perhaps more importantly, by public accounts committees in the various jurisdictions. In Australia, all ANAO reports are reviewed by the JCPAA with about onethird being subject to public inquiry and examination, including the relevant participants. Over the years, the ANAO has also arranged peer reviews of a number of its performance audits by the New South Wales State Auditor-General and by the New Zealand Auditor-General. As well, it has been involved in a number of peer reviews of other offices (ANAO, 2010b, p. 5), which has been a significant 'learning' experience providing valuable insights for performance improvement.

That said, 'real or perceived' expectation gaps can occur where there is limited evidence of implementation of 'agreed' performance audit recommendations. Many audit offices include comments from auditees; particularly the acceptance or otherwise of audit recommendations in the relevant reports. Indeed, while such inclusions have been made in ANAO performance audit reports for over eight years, it is now a requirement under legislation. It should be a reasonable expectation that 'agreed' audit recommendations would be implemented in a timely fashion. Unfortunately, despite the range of follow-up action taken by the parliament, and audit offices in particular, government departments and agencies are frequently quite tardy in their implementation, sometimes only addressing them partially and occasionally not at all. This situation is somewhat surprising given the emphasis on sound corporate governance, including the establishment of audit committees, for more than a decade in Australia. It has been identified, and reinforced, good practice for audit committees to have 'implementation of audit findings and recommendations' as a regular item on their agendas and to provide regular reports to the governance body, including the agency head.

I will comment, if only briefly, on the main 'incentives' for action on performance audit findings and recommendations because they have not been fully effective. The question has to be asked as to what more could, or should, be done, to assure the parliament and the public that appropriate action has been taken to implement performance audit recommendations. First, there is the positive incentive to improve performance both for the 
public good and for the reputation and job satisfaction of those involved in an era where there have been increasing demands for better governance and more accountable government. Audit offices have a policy of follow-up action on audit recommendations, including through any 'observer' status on their auditees' audit committees. As part of the audit programme, follow-up audits are determined on the basis of auditor observations/recommendations. Given the wide-ranging demands for audits, both assurance and performance, there is only limited scope for follow-up audits each year. Some years ago, in Australia, the then department of finance conducted a systematic review of the implementation of audit recommendations each year. Agency assertions were subject to a requirement for supporting 'evidence'. A report was provided to the minister for finance and tabled in both houses of parliament. It may well be time to consider such a policy again.

By far the most effective follow-up action in Australia, in my view, is taken by the JCPAA. Unfortunately, the JCPAAalso has to limit such activity to its capacity to meet the demands of its programme of inquiries and reports each year. One quite effective approach adopted by the JCPAA has been to ask the relevant agencies/ departments for their assessment of the most realistic timetable for implementation of performance audit recommendations and indicate that the JCPAA secretary will contact them to check on progress at that time. If the JCPAA is not satisfied with the response, they will decide whether to re-open their inquiry and possibly widen its scope to review related activities and any implications of failure to implement the audit recommendations.

All parties recognize that a number of, often unforeseen, factors can impact adversely on implementation of audit recommendations. They can be internally or externally driven. For example, there may simply be a lack of capacity by the organization concerned because of unavailability of the appropriate resources, a lack of financial or other capacities to make the changes, variations in programme objectives and/or strategies and priorities, a changing environment with different demands and/or contributions from other stakeholders, including programme beneficiaries, or simply other government demands with higher priority. It would be naïve to think that these might not be given as 'convenient' excuses in some circumstances. However, agencies should be asked to demonstrate such situations and their likely impact on the implementation of audit recommendations. The intention has to be to ensure accountability for the effective implementation of agreed audit recommendations.

Looking at the approaches of other audit offices, the New Zealand Office of the AuditorGeneral follows up on recommendations made in performance audit reports 'to understand and confirm that public entities had taken action in response to those recommendations' (NZ Controller and Auditor-General, 2010, p. 17) This is not too dissimilar to the ANAO approach. The NAO has a quite robust approach where, for example: 'We record an impact only when the related benefit has been brought about, we have data to substantiate the benefit, and the audited body gives its agreement' (NAO, 2011, p. 79).

The NAO observes that the impact of its recommendations are not always separable from other influences and, in these cases, the NAO agrees a proportion of an overall financial impact with the audited body based on an assessment of the likely level of influence of the NAO's work. The GAO uses a set of quite stringent tests in its follow-up of "past recommendations implemented' (GAO, 2011 a, appendix 1, p. 1 and pp. 4-5). Both the NAO and GAO only specify 'net benefits' achieved from implementation of audit recommendations. That is, they deduct costs associated with taking the action recommended. Two other observations of GAO experience and practice are of particular interest in relation to accountability for implementation ofaudit recommendations. First, experience has shown that if a recommendation has not been implemented within four years, it is not likely to be implemented'. Second, GAO staff must verify, with sufficient supporting documentation, that an agency's reported actions in relation to audit recommendations are adequately being implemented (GAO, $2011 \mathrm{a}$, p. 4). As well, the Congress is provided with a database which sets out the status of recommendations that have not been implemented.

\section{An implementation conundrum}

Possibly the most disappointing and frustrating aspect of performance auditing is the recurring nature of audit issues despite recommendations in previous reports, better practice guides and development of related guidance or guidelines. Various explanations have been put forward, such as the changing nature of the economic and social environment, changing political imperatives and timeframes for results, pressures on resources-including cutbacks, 
turnover of staffand loss of expertise, devolution of authority, and increased focus on shared responsibility involving other levels of government, the not-for-profit sector and private sector firms. However, this leaves a not insignificant expectations gap in relation to the effectiveness of performance auditing, particularly in the media and the parliament and, as a result, in the general public.

A full exploration of this issue could well be the subject of a separate research article. My purpose here is to draw attention to what I think is a credibility gap in accountability rather than a real or perceived expectations gap in performance auditing. I want to illustrate this in three areas-procurement, contract management, and defence projects, using largely Australian examples but noting that similar experience can be illustrated in other countries. These three areas-obviously interrelated-involved billions of dollars of budget revenue each year. They also have a marked impact on the efficiency and effectiveness of both government and business. Therefore, it would seem imperative to ensure accountability for both the processes and outcomes involved. As a broad indicator of the number of performance audits conducted on these topics in the past decade or so, the search index on the ANAO homepage (www.anao.gov.au) showed 24 reports under 'procurement', 38 reports under 'contract management', and 15 under 'defence projects'-a significant amount of activity.

Procurement: Looking at procurement first, the Australian Auditor-General, in his performance audit report on the Implementation of the Revised Commonwealth Procurement Guidelines (CPGs) noted that: 'these changes did not alter the overarching principle of value-for-money, through encouraging competition, accountability and transparency, and the efficient, effective and ethical use of resources' (ANAO, 2007).

In other words, the fundamental performance requirements of the long-standing CPGs continued to apply. This was reemphasised in a recent report on Direct Source Procurement (ANAO, 2010d, para.3,p. 16). The outcome of this latter audit is, perhaps, best summed up by a comment from the department of finance and deregulation: 'This audit report highlights practices that are of concern because they indicate a lack of understanding of key rules and procedures in Commonwealth procurement, underpinned by legislation, and an appreciation that these are intended to promote value for money and accountability' (ANAO, 2010d, para. 67, p. 36).

There was extensive media coverage and criticism of the lack of accountability on what have been considered to be established best practices for procurement. Given the longstanding successive government and parliamentary concerns about procurement outcomes, I find it difficult to accept that the term "guidelines" in the title of the CPGs can be misconstrued by entities as representing nonmandatory requirements' (Finance and Deregulation, 2011). I note that regulation 7 of the Financial Management and Accountability Regulations requires that officials must act in accordance with the CPGs when undertaking procurements. Reword: slightly unclear?

Contract management: Contract management is integral to both procurement and defence project accountability and performance concerns. The ANAO recently made reference to the long-standing advice provided to agencies by the department of finance and deregulation that 'evergreen provisions' (that is, no limit on the number of performance-based contract extensions) do not provide the necessary assurance that "the value for money requirements of the policy framework in the CPGs will be met and that they are likely to limit competition' (ANAO, $2011 \mathrm{~b})$. Nevertheless, no such restriction applied to the particular contract being audited which had a history of serious cost overruns. Belatedly, corrective action was being put in place. In another report, the ANAO's recommendations related to quite fundamental contract management performance covered in better practice guides (ANAO, 2009).

Defence projects: There has been a high level of frustration with defence projects in all of the countries referred to in this article, fuelled by successive performance audit reports frequently revealing the same ongoing management and administrative problems and deficiencies (Smelt, 2008). Undoubtedly, many projects are in the high technology area, which involve a degree of uncertainty and significant management challenges, including staff rotation and turnover, with considerable private sector and other national government participation. This is not just an exercise in allocating blame for inadequate performance and lack of effective action to remedy observed deficiencies. The emphasis should be on how to enhance performance and provide greater confidence to the Australian government, 
parliament and general public. Of interest in this regard is the development of an annual programme (and associated funding) to enable the ANAO to review major defence projects being managed by the Defence Materiel Organization (DMO). This effectively makes the ANAO part of the ongoing accountability and assurance framework for defence.

The first ANAO report in relation to this initiative was tabled in parliament in November 2008 (covering nine projects). The approach adopted builds on international experience, particularly in the UK and USA. It is hoped that not only will there be an earlier information flow to all stakeholders and greater accountability, but that it "will also assist DMO in pursuing its agenda to improve its performance in managing major acquisition projects' (ANAO, 2008c). The report also indicates an increased focus on accountability and management, in particular risk management. Audit reports in each of the next two years covered 15 and 22 major projects respectively, with the aim of bringing the total number of projects to 28 in the 2011 report. All are subject to JCPAA review. Not surprisingly, that committee has taken a close interest in the reports and 'provided constructive input to both the ANAO and the DMO on ways in which the Major Projects Report (MPR) could be improved' (ANAO, 2010e, para. 7, p. 15).

The ANAO has stressed that the level of assurance provided by these reviews is 'less than that typically provided by our performance audits' (ANAO 2010e, para. 10, p. 16). Nevertheless, valuable information is being provided, particularly for longitudinal analysis of projects over time. The focus applied to schedule performance by DMO as an effective means of them managing schedule (slippage) and budget performance (costs) is essential for their overall performance. Interestingly, while the projects' budgeted cost requires 'careful management' by the DMO, this dimension of project performance has not been a major issue (ANAO, 2010e, para. 17, p. 18). However, the ANAO has also observed that the total time for the 22 major projects to achieve their final operational capability date is expected to be almost one-third longer than was originally planned. There is clearly some way to go to engender 'real' and 'sustained' confidence, at least at the political level, if a recent comment by the minister for defence is any indication, when he placed a whole list of defence culture and management woes under the label of 'improving personal and institutional accountability' (Australian Financial Review,
2011). The focus is well and truly on accountability for performance.

\section{Concluding thoughts}

This article is about 'expectation gaps' in relation to performance auditing, largely from an Australian perspective. Gaps in understanding arise from lack of knowledge and/or understanding and from 'embedded prejudice' or, simply, strongly held beliefs or personal philosophy. We can, and should, do something about the former but little, if anything, more can be done about the latter. Some expectations are quite unrealistic, being overly optimistic or simply too pessimistic. Nevertheless, we have to be both pro-active and transparent-and honest-in what we do and say we do. In my experience, these have been the approaches taken by public sector auditors even if there are occasional shortcomings. An important asset in this respect is their legislative independence. Restrictions can be imposed on the audit mandate and on the resources available for audit, as well as non-acceptance of audit findings and recommendations, all of which impact adversely on stakeholder expectations and create 'gaps'. Fortunately, at least in most western democracies, the reverse is mainly the case. There has been strong ongoing support for public auditing and, indeed, for performance auditing.

Three areas have been identified where 'expectation gaps' can occur-the application of professional standards, accountability for audit performance and the implementation of audit recommendations. There is demonstrable positive supporting evidence of addressing the first two areas, reinforced by wide-ranging consultation and public explanation. Nevertheless, ongoing gaps-real or apparent-in stakeholder expectations in these respects need to be addressed continually in an economic, efficient and effective manner by audit offices. Hopefully this might be accomplished by illustrating, and reinforcing, the kind of approaches and actions discussed in this article. The question which clearly requires attention is whether 'expectation gaps' have been adequately, and effectively, addressed is in the implementation of audit recommendations.

Particularly where audit recommendations are accepted by the relevant organization, it is disappointing to discover in later audits that no suitable implementation action has been taken. The expectation is that implementation has taken place unless, for instance, circumstances have changed to make the recommendations 
redundant. In most countries, appropriate follow-up action is taken. To a point, this should impose a 'discipline' on the implementation process. While I fully support the view that an audit which finds evidence of high levels of performance-whether in administrative processes, programme outputs or outcomeswith only limited recommendations, adds value and should give added confidence to all stakeholders in the accountability framework for public sector performance. That said, there should not be an expectation that audits would only be conducted in areas where there are apparent problems and/or lack of performance.

The article has referred to the highly disciplined approach taken by the GAO in following up and assuring implementation of audit recommendations. The NAO also has a similar approach to ensuring that the 'savings' attributable to implementation of audit recommendations are actually achieved. There would be doubts that smaller audit offices would have the resource capacity to undertake similar action. It might be argued that creating scope to do so by undertaking fewer audits would result in more effective audit outcomes. Unfortunately, this could also result in a difficulty for those offices in recruiting and retaining professional auditors.

A credible outcome-which would minimize any expectation gap-would preferably involve some kind of independent assessment and information based on appropriate expertise. This puts the problem back in the auditors' bailiwick. Another possibility would be to have a 'sign-off' on implementation of audit recommendations by the organization's internal auditor or, preferably, by an audit committee. These alternatives may not be seen as sufficiently 'independent' to eliminate any expectation gap but, pragmatically, might be given the opportunity to do so. In Australia, consideration should at least be given to restoring the Finance Department responsibility for regular reporting to the minister and to the parliament on the implementation of audit recommendations. More ambitiously, perhaps, consideration should be given to provide the JCPAA with more resources to follow-up such reporting. Hopefully, performance information provided by departments and agencies in the future will reflect improved programme outcomes as a result, and ameliorate any real or perceived expectation gap about the value added by performance auditing.

\section{References}

Australian Financial Review (2011), Smith stands firm on battle with defence (28 June), p. 61.

Auditing and Assurance Standards Board (2008), ASAE 3500:Performance Engagement (Melbourne), section 19, p. 15.

ANAO (2004), Better Practice in Annual Performance Reporting (8 April).

ANAO (2006), The Auditor-General Annual Report 2005-06 (7 September), p. 32.

ANAO (2007), Implementation of the Revised Commonwealth Procurement Guidelines. Report No. 21, 200607 (31 January), p. 11.

ANAO and the Department of Finance and Deregulation (2007), Developing and Managing Contracts. Better Practice Guide (2 February).

ANAO (2008a), Performance Auditing in the Australian National Audit Office, p. 3

ANAO (2008b), Specific Purpose Payments: General Recurrent Grants for Government Schools. Report No. 45 (26 June), pp. 16 to 23.

ANAO (2008c), Defence Materiel Organization Major Projects Report 2007-08. Report No. 9 (27 November), p. 11.

ANAO (2009), Agencies Contract Management. Report No. 14, 2009-10 (25 November).

ANAO (2010a),Audit Work Program July 2010 (July). ANAO (2010b), The Auditor-General Annual Report 2009-10 (29 September), p. 5.

ANAO (2010c), Home Insulation Program. Report No. 12 (15 October).

ANAO (2010d), Direct Source Procurement. Report No. 11 (30 September), para. 3, p. 16.

ANAO (2010e), 2009-10 Major Projects ReportDefence Materiel Organization. Report No. 17 (19 November), para. 7, p. 15.

ANAO (2011a), See www.anao.gov.au

ANAO (2011b), Management of the Explosive Ordnance Services Contract. Report No. 40 (17 May), para. 16, p. 15.

Barrett, P. (2010a), Audit Independence is not a one-way street. Address to an international seminar on 'Strengthening external public auditing in the ASOSAI region', Seoul (13 December).

Barrett, P. (2010b), Performance auditing — what value? Public Money \& Management, 30, 5, pp. 271-278.

Finance and Deregulation (2011), Commonwealth Financial Accountability Review—Strengthening Procurement (Canberra), p. 12.

JCPAA (2010), Inquiry into the Auditor-General Act 1997. Report 419 (Canberra), pp. xv-xvii.

McPhee, I. (2010), 'Thirty-something'-developments in performance auditing. Address to the Canberra Evaluation Forum (26 February), p. 7.

Morse, A. (2010), Performance auditing-what value? Public Money \& Management, 30, 6, p. 324.

NZ Controller and Auditor-General (2010), An- 
nual Report 2009/10 (30 September), pp. 14-18.

Smelt, S. (2008), The defence difference. See http:/ /simonsmelt.com/

NAO (2009), Performance Frameworks and Board Reporting (London).

NAO (2011), Annual Report 2011 (London).

GAO (2010), Summary of GAO's Performance and Financial Information-Fiscal Year 2009 (Washington, D.C.), pp. 8-10 and p. 14.

GAO (2011a), Summary of GAO's Performance and Financial Information (Washington, D.C.), p. 2.

GAO (2011b), Fiscal Year 2012 Performance Plan (Washington, D.C.), p. 6.

GAO (2011c), Fiscal Year 2012 Performance Plan (Washington, D.C.), appendix 1, pp. 1-4. 